\title{
A Case Report of Adult Pineoblastoma Occurring in a Pregnant Woman
}

\author{
FRANCESCO CUCCIA ${ }^{1}$, GIANLUCA MORTELLARO ${ }^{2}$, DANIELA CESPUGLIO ${ }^{2}$, \\ VITO VALENTI ${ }^{1}$, GIORGIA DE GREGORIO ${ }^{1}$, EMANUELE QUARTUCCIO ${ }^{1}$, LIVIO BLASI $^{3}$, \\ NATALE FRANCAVIGLIA ${ }^{4}$, CRISTINA GALLO ${ }^{5}$, ANTONIO LO CASTO ${ }^{6}$ and GIUSEPPE FERRERA ${ }^{2}$ \\ ${ }^{1}$ Radiation Oncology School, University of Palermo, Palermo, Italy; \\ ${ }^{2}$ Radiation Oncology, ${ }^{3}$ Oncology Unit, ${ }^{4}$ Division of Neurosurgery and \\ ${ }^{5}$ Radiology Unit, ARNAS Civico Hospital, Palermo, Italy; \\ ${ }^{6}$ Radiation Oncology School, Section of Radiological Sciences, DIBIMED, University of Palermo, Palermo, Italy
}

\begin{abstract}
Background/Aim: Pineoblastoma of the adult age is an uncommon tumor with only 200 cases reported. A standardized approach for an optimal adjuvant strategy is currently lacking. The case presented herein also deals with the issue of central nervous system tumors in pregnancy. Case Report: A 21-year-old pregnant woman presented with massive hydrocephalus due to a mass in the pineal region detected with MRI. After positioning an urgent ventricular derivation, a cesarean section was performed. During a third ventriculocisternostomy, a biopsy revealed a pineoblastoma. After a maximal safe resection, postoperative craniospinal irradiation for a total dose of 36 Gy plus a sequential boost to the tumor bed to $54 \mathrm{~Gy}$, and adjuvant chemotherapy with $C D D P$ plus $C C N U$ plus vincristine were performed. After one year, the patient is alive with no evidence of disease. Conclusion: The use of adjuvant radio-chemotherapy provided excellent outcomes in our case. The advanced gestational age facilitated the choice of the therapeutic strategy.
\end{abstract}

The suprasellar region is a rare site of intracranial tumors, accounting only for $<1 \%$ of all brain neoplasms (1). Among the wide group of tumors occurring in this location, masses arising from pineal parenchyma represent only $0.3 \%$ of all central nervous system cancers (2). According to the updated 2016 World Health Organization (WHO) taxonomy (3) pineal neoplasms are categorized by histological grade in pineocytoma, pineal parenchymal tumor of intermediate differentiation, papillary pineal tumor and grade IV

Correspondence to: Dr. Daniela Cespuglio, Radiation Oncology, ARNAS Civico Hospital, Piazza Nicola Leotta, 4, Palermo, 90100, Italy. Tel: +390916664206, e-mail: danielacespuglio@virgilio.it

Key Words: Pineoblastoma, pregnancy, craniospinal irradiation. pineoblastoma. All these tumors occur most frequently in pediatric patients, and are less common in adults. Usual clinical presentation is related to the obstruction of the sylvian aqueduct with consequent hydrocephalus and intracranial hypertension. Pineoblastoma accounts for $40 \%$ of parenchymal pineal cancers, and it represents the most aggressive subtype with a poor prognosis due to the frequent invasion of adjacent structures and cerebrospinal fluid dissemination, reporting 5 -years survival rates $<60 \%$ (4). The highest peak of incidence is described in the childhood, particularly in children less than 2 years old, where it can occur also in combination with retinoblastoma (5).

As mentioned above, starting from the second decade, adult cases are very rare and represent less than $10 \%$ of published literature (6). For this reason, limited data are currently available in the effort of developing a standard management of the disease, with a lack of consensus about the optimal combination of a multimodality treatment involving surgery, radiotherapy and/or chemotherapy. Here we report our case of a pineoblastoma occurring in a 9months pregnant 21-year-old woman. Central nervous system tumors during pregnancy are rare, despite some histological subtypes that are specifically related to gravidity condition, like choriocarcinomas, pituitary benign tumors and meningiomas (7). In most cases, brain tumors display the same incidence in both pregnant and non-pregnant patients, but some authors have hypothesized that physiology changes related to pregnancy may influence the growth of intracranial masses both in terms of hemodynamic and of immuno-tolerance, with a potential more severe spectrum of symptoms at clinical presentation (8).

Consequently, pregnant patients represent a hard challenge in terms of management in the effort to provide an effective treatment keeping in mind the safety of the mother and the child. 


\section{Case Presentation}

After the recent onset of headache, nausea and dizziness with diplopia and difficulty in walking, a 21-year-old woman in a nine months state of pregnancy came at our hospital. A brain magnetic resonance imaging (MRI) revealed a triventricular hydrocephalus due to the presence of a contrast-enhanced mass in the pineal region $(2.4 \times 1.7 \times 1.7 \mathrm{~cm})$. The tumor appeared hyperintense in T2-weighted series and hypointense in T1 with colliquative features causing a massive compression on the mesencephalic aqueduct and an upwards stretch of the corpus callosum. After the positioning of an external ventricular derivation in urgency, a cesarean section was successfully performed. Afterwards, a cytology and MRI evaluation of the spine to assess the cerebrospinal fluid involvement were performed, with no evidence of dissemination. Due to the state of pregnancy, laboratory tests for $\alpha$-fetoprotein and $\beta$-human chorionic gonadotropin were considered uninterpretable for the differential diagnosis process. The patient was a candidate to a third ventriculocisternostomy and a biopsy revealed the histological features of a grade IV WHO pineoblastoma. The subsequent maximal safe resection, using a supracerebellar infratentorial approach in sitting position, confirmed -on pathological examination- the grade IV WHO pineoblastoma with an intense mitosis activity, $\mathrm{Ki} 67=70 \%$, high nuclearcytoplasmatic ratio and positive immunoreactivity for synaptophysin, CD56, chromogranin A.

A post-operative MRI of the brain and neuraxis performed after one month from surgery revealed the presence of a residual area of contrast-enhancement in the tumor bed, so the patient was candidated to an adjuvant radiotherapy treatment consisting of craniospinal irradiation with a sequential boost to the tumor bed. Radiation therapy was delivered with Image-guided Intensity Modulated Radiotherapy (IG-IMRT) by means of helical tomotherapy (Accuray Inc., Sunnyvale, CA, USA). Patient immobilization was obtained in the supine position with a head-neckshoulder thermoplastic mask (Qfix Avondale, PA, USA) for the acquisition of a $2.5-\mathrm{mm}$ slice thickness CT scan. Treatment plan was generated on the tomotherapy planning station, in order to deliver a total dose of 36 Gy in 20 fractions to the neuraxis plus a sequential boost to the tumor bed to reach a total dose of 54 Gy using 1.8 Gy fractions. Craniospinal target delineation was performed with the adoption of variable margins (isotropic $5 \mathrm{~mm}$ for brain and cervico-thoracic spine and isotropic $7 \mathrm{~mm}$ for lumbar-sacral spine) in order to compensate any positioning variability; for tumor bed boost, the target was delineated basing on preoperative and post-operative MRI image-fusion adding a 5-mm isotropic margin. Treatment delivery was administered with a daily verification of target coverage through the execution of megavoltage CT scans prior to each fraction. Our treatment was well-tolerated with no interruption observed; the patient suffered only from occasional nausea and headache fully resolved after oral steroid therapy.

A brain and spine MRI performed after two months from the end of RT reported no evidence of disease. Subsequently, the patient started chemotherapy with CDDP plus CCNU plus vincristine. After one year from the end of treatment the patient is alive with no evidence of disease.

\section{Discussion}

To our knowledge, this is the first case of a pineoblastoma occurring in a pregnant woman, presenting two important issues of interest. First of all, the histological subtype, since pineoblastoma of the adult age accounts approximately 200 cases reported starting from 1979 (9). Consequently, it is hard to produce a standardized management of these patients, despite the role of surgery being established as a mainstay for all pineal parenchymal tumors (10), as the extent of surgical resection represents a crucial factor for its impact on survival (11).

Adjuvant radiotherapy is highly recommended, although the optimal dose and target volume still remain under debate. The largest experience of radiotherapy for pineal tumors is reported by Glanzmann et al. (12) who suggest a range of 44-50 Gy, keeping in mind that the authors referred to a $2 \mathrm{D}$ based radiotherapy. More recently, Kumar et al. (13) recommend a range of 50-54 Gy in conventional fractionation, preferably using newer techniques like IMRT, or at least 3D conformal RT. Concerning target volume delineation, despite the most common approach being based on craniospinal irradiation plus a local boost, some authors reported a focal treatment to tumor site alone: Lee et al. (14), evaluated 34 cases of pineoblastoma occurred in patients aged 16 years or more, including 24 subjects treated only with cranial radiotherapy, reporting that a cranial dose $\geq 40$ Gy was associated with improved survival. However, the authors did not evaluate the choice of omitting neuraxis irradiation.

In our patient, adjuvant radiotherapy was performed with helical tomotherapy, a unique linear accelerator that integrates an IMRT helical system with a CT scan-based image guidance, offering the possibility to perform a daily verification in order to check setup positioning and adequate target coverage. Particularly for complex shape volumes, Helical Tomotherapy provides remarkable results in terms of avoiding junctions and gaps, organs at risk sparing and also gaining a more homogeneous dose distribution and target coverage (15).

Also, the role of chemotherapy is controversial and mainly investigated in paediatric patients (16-18), where pineoblastoma has a poorer prognosis (9). For adult patients, only limited data are available with inconclusive results (14, 19). Considering the biological similarity of medulloblastomas and pineoblastomas, for our patient adjuvant chemotherapy was proposed with CDDP plus CCNU plus vincristine. 
Table I. Literature experiences of management of intracranial neoplasms in pregnant patients.

\begin{tabular}{|c|c|c|c|c|}
\hline Authors (year) & $\begin{array}{l}\mathrm{N}^{\circ} \text { of } \\
\text { cases }\end{array}$ & $\begin{array}{l}\text { Histological } \\
\text { subtypes }\end{array}$ & $\begin{array}{l}\text { Gestational age } \\
\text { (weeks) }\end{array}$ & $\begin{array}{c}\text { Craniotomy/delivery } \\
\text { sequence }\end{array}$ \\
\hline Beni-Adan et al. (21) (2001) & 1 & Neurinoma & 35 & After \\
\hline Vougioukas et al. (22) (2004) & 3 & 2 Glioma 1 Meningioma & $23-33$ & 3 Before \\
\hline Annunziato et al. (23) (2005) & 1 & Hemangioperycitoma & 40 & After \\
\hline Erickson et al. (24) (2005) & 1 & Rhabdoid tumor & 30 & Before \\
\hline Simon et al. (25) (2005) & 1 & Hemangioma & 38 & Before \\
\hline Ducray et al. (26) (2006) & 3 & 2 Glioblastoma 1 Oligodendroglioma & $12-29$ & Before \\
\hline Bodner-Adler et al. (27) (2006) & 1 & Primitive neuroectodermal tumor & 20 & Before \\
\hline Lynch et al. (28) (2010) & 10 & $\begin{array}{c}4 \text { Astrocytoma } \\
2 \text { Meningioma } \\
1 \text { Pituitary adenoma } \\
3 \text { Other }\end{array}$ & $16-40$ & $\begin{array}{l}4 \text { Before } \\
6 \text { After }\end{array}$ \\
\hline Lee et al. (29) (2012) & 1 & Meningioma & 28 & Before \\
\hline Verheecke et al. (30) (2014) & 27 & $\begin{array}{l}10 \text { Glioma } \\
6 \text { Astrocytoma } \\
2 \text { Meningioma } \\
9 \text { Other }\end{array}$ & $30-36$ & $\begin{array}{c}12 \text { Before } \\
7 \text { After } \\
2 \text { No Craniotomy } \\
2 \text { Deceased } \\
4 \text { Termination }\end{array}$ \\
\hline Ravidra et al. (8) (2015) & 1 & Ganglioglioma & 39 & After \\
\hline Kalbasi et al. (31) (2017) & 1 & Atypical theratoid/Rhabdoid tumor & 14 & Before \\
\hline Present experience & 1 & Pineoblastoma & 39 & After \\
\hline
\end{tabular}

The other element of interest of the present report is the gravidity of the patient. Usually, the most frequent intracranial issues of pregnant women involve vascular pathologies, like arteriovenous malformations, cerebral aneurysms or preeclampsia-induced bleeding (20). Brain tumors are very uncommon during pregnancy and Table I (8, 21-31) collects the literature data about the other experiences of intracranial neoplasms in pregnant patients. In the present case, the state of pregnancy had a relevant impact on the differential diagnosis process, since the role of markers like $\alpha$-fetoprotein and $\beta$-human chorionic gonadotropin was limited by the gravidity state. Also, as reported in a recent review by Ravindra et al. (8), some central nervous system tumors symptoms due to the intracranial hypertension may mimic a hyperemesis gravidum, making more challenging the diagnostic path. In this context, multidisciplinary management of pregnant patients represents a milestone to provide an effective treatment of the underlying disease and at the same time a safe delivery of the child.

The role of surgery is crucial, since the extent of resection is a consolidated positive prognostic factor, and can be safely performed during the second and third trimester of pregnancy (32). For patients with early gestational age, the choice of postponing surgery may be considered to reduce abortion risks, unless neurological symptoms require urgent intervention due to the mother's life-threatening condition. In our case, the patient was in advanced gestational age, but, due to the presence of a massive hydrocephalus compressing mesencephalic structures, an urgent external ventricular derivation was mandatory. Once the patient was stabilized, the safe delivery of the child was performed with a cesarean section; afterwards, treatment strategy included the substitution of the external derivation with a third ventriculocisternostomy and a biopsy of the lesion, and, a week later, the surgical resection of the pineal mass was carried out.

The largest experience in the literature about the management of intracranial tumors in pregnancy is reported by Verheecke et al. (30) in their series of 27 women, including also patients who received curative treatments (surgery, radio- or chemotherapy) during gravidity. Particularly, the authors describe the outcomes of 7 patients who received brain RT during pregnancy, stating that this treatment is safe for the fetus never exceeding the threshold dose of $0.1 \mathrm{~Gy}$ for the future child. However, in this series no patient received craniospinal irradiation. Bodner-Adler et al. (27) reported the case of a primitive neuroectodermal tumor in a pregnant woman in the second trimester managed with surgery and adjuvant brain radiotherapy during pregnancy, while neuraxis radiotherapy was postponed after the delivery at the 34th week of gestational age. Recently, Kalbasi et al. (31) reported the excellent outcomes of an atypical theratoid/rhabdoid tumor in a 25-year-old pregnant woman (14 weeks gestational age) who underwent surgical exeresis of the brain lesion and subsequently, at the 28th 
week of fetal age, she received adjuvant proton beam craniospinal irradiation, with no evidence of recurrence and no late sequelae for the baby after three years of follow-up.

\section{Conclusion}

The advanced gestational stage of our patient facilitated the management of this rare tumor, since adjuvant therapies were safely performed after delivery. The integration of radiotherapy and chemotherapy after maximal safe resection revealed excellent outcomes. Since adult age pineoblastoma is under-represented in the literature more data are required to configure an optimal standard treatment strategy; particularly the role of chemotherapy should be further investigated.

\section{Conflicts of Interest}

The Authors report no conflicts of interest in this work.

\section{Authors' Contributions}

Study conception: Giuseppe Ferrera, Natale Francaviglia, Livio Blasi; Writing of the manuscript: Francesco Cuccia, Daniela Cespuglio, Gianluca Mortellaro; Data acquisition: Emanuele Quartuccio, Giorgia De Gregorio, Vito Valenti, Livio Blasi, Cristina Gallo; Literature review: Francesco Cuccia, Emanuele Quartuccio, Giorgia De Gregorio, Vito Valenti; Imaging evaluation: Cristina Gallo, Antonio Lo Casto; Manuscript supervision: Giuseppe Ferrera, Natale Francaviglia, Antonio Lo Casto. Final approval: All authors.

\section{Acknowledgements}

The Authors had no financial support regarding this study.

\section{References}

1 Al-Hussaini M, Sultan I, Abuirmileh N, Jaradat I and Qaddoumi I: Pineal gland tumors: experience from the SEER database. J Neurooncol 94: 351-358, 2009. PMID: 19373436. DOI: 10.1007/s11060-009-9881-9

2 Cuccia V, Rodríguez F, Palma $F$ and Zuccaro G: Pinealoblastomas in children. Childs Nerv Syst 22(6): 577-585, 2006. PMID: 16555075.

3 Louis DN, Perry A, Reifenberger G, von Deimling A, FigarellaBranger D, Cavenee WK, Ohgaki H, Wiestler OD, Kleihues P and Ellison DW: The 2016 World Health Organization classification of tumors of the central nervous system: A summary. Acta Neuropathol 131(6): 803-820, 2016. PMID: 27157931. DOI: 10.1007/s00401-016-1545-1

4 Tamrazi B, Nelson M and Blüml S: Pineal region masses in pediatric patients. Neuroimaging Clin N Am 27(1): 85-97, 2017. PMID: 27889025. DOI: 10.1016/j.nic.2016.08.002

5 de Jong MC, Kors WA, de Graaf P, Castelijns JA, Kivelä T and Moll AC. Trilateral retinoblastoma: A systematic review and meta-analysis. Lancet Oncol 15(10): 1157-1167, 2014. PMID: 25126964. DOI: 10.1016/S1470-2045(14)70336-5
6 Ai P, Peng X, Jiang Y, Zhang H, Wang S and Wei Y: Complete regression of adult pineoblastoma following radiotherapy: A case report and review of the literature. Oncol Lett 10(4): 2329-2332, 2015. PMID: 26622845. DOI: 10.3892/ol.2015.3574

$7 \mathrm{Ng} \mathrm{J}$ and Kitchen N: Neurosurgery and pregnancy. J Neurol Neurosurg Psychiatry 79(7): 745-752, 2008. PMID: 18559459. DOI: $10.1136 /$ jnnp.2007.117002

8 Ravindra VM, Braca JA 3rd, Jensen RL and Duckworth EA: Management of intracranial pathology during pregnancy: Case example and review of management strategies. Surg Neurol Int 6: 43, 2015. PMID: 25883835. DOI: 10.4103/2152-7806.153845

9 Gener MA, Conger AR, Van Gompel J, Ariai MS, Jentoft M, Meyer FB, Cardinal JS, Bonnin JM and Cohen-Gadol AA: Clinical, pathological, and surgical outcomes for adult pineoblastomas. World Neurosurg 84(6): 1816-1824, 2015. PMID: 26287970. DOI: 10.1016/j.wneu.2015.08.005

10 Clark AJ, Ivan ME, Sughrue ME, Yang I, Aranda D, Han SJ, Kane AJ and Parsa AT: Tumor control after surgery and radiotherapy for pineocytoma. J Neurosurg 113(2): 319-324, 2010. PMID: 20136388. DOI: 10.3171/2009.12.JNS091683

11 Lutterbach J, Fauchon F, Schild SE, Chang SM, Pagenstecher A, Volk B, Ostertag C, Momm F and Jouvet A: Malignant pineal parenchymal tumors in adult patients: patterns of care and prognostic factors. Neurosurgery 51(1): 44-55, 2006. PMID: 12182434.

12 Glanzmann C and Seelentag W: Radiotherapy for tumours of the pineal region and suprasellar germinomas. Radiother Oncol 16(1): 31-40, 1989. PMID: 2813835.

13 Kumar N, Srinivasa GY, Madan R and Salunke P: Role of radiotherapy in residual pineal parenchymal tumors. Clin Neurol Neurosurg 166: 91-98, 2018. PMID: 29408780. DOI: 10.1016/j.clineuro.2018.01.027

14 Lee JY, Wakabayashi T and Yoshida J: Management and survival of pineoblastoma: an analysis of 34 adults from the brain tumor registry of Japan. Neurol Med Chir (Tokyo) 45(3): 132-141, 2005. PMID: 15782004.

15 Schiopu SR, Habl G, Häfner M, Katayama S, Herfarth K, Debus $\mathrm{J}$ and Sterzing F: Craniospinal irradiation using helical tomotherapy for central nervous system tumors. J Radiat Res 58(2): 238-246, 2017. PMID: 28096196. DOI: 10.1093/jrr/ rrw095

16 Jakacki RI, Zeltzer PM, Boyett JM, Albright AL, Allen JC, Geyer JR, Rorke LB, Stanley P, Stevens KR and Wisoff J: Survival and prognostic factors following radiation and/or chemotherapy for primitive neuroectodermal tumors of the pineal region in infants and children: a report of the Childrens Cancer Group. J ClinOncol 13(6): 1377-1383, 1995. PMID: 7751882. DOI: $10.1200 / J C O .1995 .13 .6 .1377$

17 Gururangan S, McLaughlin C, Quinn J, Rich J, Reardon D, Halperin EC, Herndon J 2nd, Fuchs H, George T, Provenzale J, Watral M, McLendon RE, Friedman A, Friedman HS, Kurtzberg J, Vredenbergh J and Martin PL: High-dose chemotherapy with autologous stem-cell rescue in children and adults with newly diagnosed pineoblastomas. J Clin Oncol 21(11): 2187-2191, 2003. PMID: 12775745 . DOI: 10.1200/JCO.2003.10.096

18 Biswas A, Mallick S, Purkait S, Gandhi A, Sarkar C, Singh M, Julka PK and Rath GK: Treatment outcome and patterns of failure in patients of pinealoblastoma: review of literature and clinical experience from a regional cancer centre in north India. Childs Nerv Syst 31(8): 1291-1304, 2015. PMID: 26040934. DOI: $10.1007 / \mathrm{s} 00381-015-2751-1$ 
19 Hinkes BG, von Hoff K, Deinlein F, Warmuth-Metz M, Soerensen N, Timmermann B, Mittler U, Urban C, Bode U, Pietsch T, Schlegel PG, Kortmann RD, Kuehl J and Rutkowski S: Childhood pineoblastoma: experiences from the prospective multicenter trials HIT-SKK87, HIT-SKK92 and HIT91. J Neurooncol 81(2): 217-223, 2007. PMID: 16941074. DOI: $10.1007 / \mathrm{s} 11060-006-9221-2$

20 Dias MS and Sekhar LN: Intracranial hemorrhage from aneurysms and arteriovenous malformations during pregnancy and the puerperium. Neurosurgery 27(6): 855-865, 1990. PMID: 2274125.

21 Beni-Adani L, Pomeranz S, Flores I, Shoshan Y, Ginosar Y and Ben-Shachar I: Huge acoustic neurinomas presenting in the late stage of pregnancy. Treatment options and review of literature. Acta Obstet Gynecol Scand 80(2): 179-184, 2001. PMID: 11167216.

22 Vougioukas VI, Kyroussis G, Gläsker S, Tatagiba M and Scheufler KM: Neurosurgical interventions during pregnancy and the puerperium: clinical considerations and management. Acta Neurochir (Wien) 146(12): 1287-1291, 2004. PMID: 15338336. DOI: 10.1007/s00701-004-0354-9

23 Annunziato M, Alessio A, Stefano M, Massimiliano G, Marco G, Carmelo A and Giulio M: Hemangiopericytoma in pregnancy: a case report. J Neurooncol 73(3): 277-278, 2005. PMID: 15980981. DOI: $10.1007 / \mathrm{s} 11060-004-5181-6$

24 Erickson ML, Johnson R, Bannykh SI, de Lotbiniere A and Kim JH: Malignant rhabdoid tumor in a pregnant adult female: literature review of central nervous system rhabdoid tumors. J Neurooncol 74(3): 311-319, 2005. PMID: 16132523. DOI: 10.1007/s11060-004-7560-4

25 Simon SL, Moonis G, Judkins AR, Scobie J, Burnett MG, Riina HA and Judy KD: Intracranial capillary hemangioma: case report and review of the literature. Surg Neurol 64(2): 154-159, 2005. PMID: 16051010. DOI: 10.1016/j.surneu.2004.10.025

26 Ducray F, Colin P, Cartalat-Carel S, Pelissou-Guyotat I, Mahla K, Audra P, Gaucherand P, Honnorat J and Trouillas P: Management of malignant gliomas diagnosed during pregnancy. Rev Neurol (Paris) 162(3): 322-329, 2006. PMID: 16585887.
27 Bodner-Adler B, Bodner K and Zeisler H: Primitive neuroectodermal tumor (PNET) of the brain diagnosed during pregnancy. Anticancer Res 26(3B): 2499-2501, 2006. PMID: 16821639.

28 Lynch JC, Gouvêa F, Emmerich JC, Kokinovrachos G, Pereira C, Welling L, Kislanov S: Management strategy for brain tumour diagnosed during pregnancy. Br J Neurosurg 25(2): 225-230, 2011. PMID: 20825287. DOI: 10.3109/02688697.2010.508846

29 Lee KH, Lall RR, Chandler JP, Bigio EH and Mao Q: Pineal chordoid meningioma complicated by repetitive hemorrhage during pregnancy: case report and literature review. Neuropathology 33(2): 192-198, 2013. PMID: 22784446. DOI: 10.1111/j.1440-1789.2012.01337.x

30 Verheecke M, Halaska MJ, Lok CA, Ottevanger PB, Fruscio R, Dahl-Steffensen K, Kolawa W, Gziri MM, Han SN, Van Calsteren K, Van den Heuvel F, De Vleeschouwer S, Clement PM, Menten J and Amant F; ESGO Task Force 'Cancer in Pregnancy': Primary brain tumours, meningiomas and brain metastases in pregnancy: report on 27 cases and review of literature. Eur J Cancer 50(8): 1462-1471, 2014. PMID: 24636876. DOI: 10.1016/j.ejca.2014.02.018

31 Kalbasi A, Kirk M, Teo BK, Diffenderfer E, Ding X, McDonough J, Murphy $\mathrm{E}$ and Hill-Kayser C: Proton craniospinal irradiation during the third trimester of pregnancy. Pract Radiat Oncol 8(3): 213-216, 2018. PMID: 29066161. DOI: 10.1016/j.pro.2017.09.005

32 Ní Mhuireachtaigh R and O'Gorman DA: Anesthesia in pregnant patients for nonobstetric surgery. J Clin Anesth 18(1): 60-66, 2006. PMID: 16517336. DOI:10.1016/j.jclinane.2004.11.009

Received March 25, 2019

Revised April 13, 2019

Accepted April 19, 2019 